\title{
Antitumor activity of kinetochore-associated protein 2 siRNA against lung cancer patient-derived tumor xenografts
}

\author{
YUKIMASA MAKITA, MIKA TERATANI, SHUMPEI MURATA, YASUTAKA HOASHI, \\ SATORU MATSUMOTO and YUJI KAWAMATA
}

Pharmaceutical Research Division, Takeda Pharmaceutical Company Limited, Fujisawa, Kanagawa 251-8555, Japan

Received September 13, 2017; Accepted November 21, 2017

DOI: $10.3892 / \mathrm{ol} .2018 .7890$

\begin{abstract}
It has been widely reported that patient-derived tumor xenografts (PDXs) are more similar to tumor tissues than conventional cancer cell lines. Kinetochore-associated protein 2 (KNTC2) is known to be upregulated specifically in tumor tissues of cancer patients and is recognized as a potential target for cancer therapy. Previously, in vivo antitumor activities of KNTC2 short interfering RNA encapsulated into a lipid nanoparticle (KNTC2-LNP) were reported in orthotopic hepatocellular carcinoma mouse models. However, it remains unclear whether KNTC2-LNP exhibits antitumor activities against lung cancer PDXs. In the present study, the antitumor activities of KNTC2-LNP were clarified in a three-dimensional culture system and a subcutaneous tumor model of lung cancer PDX, LC-60, which was resistant to erlotinib. Growth inhibitory activities of KNTC2-LNP were associated with knockdown activities. Furthermore, KNTC2-LNP also exhibited in vivo antitumor activity against another lung cancer PDX, LC-45, which was sensitive to erlotinib. These results suggest that KNTC2 is a promising target for patients with lung cancer.
\end{abstract}

\section{Introduction}

Tumor tissues are highly heterogeneous. Several types of cell interact with each other, generating a diverse array of drug sensitivities (1). Reconstruction of this heterogeneity in a preclinical study may provide a method to predict the efficacy of novel anticancer drugs in clinical study (2). Patient-derived tumor xenografts (PDXs) are established by maintaining the

Correspondence to: Mr. Yukimasa Makita, Pharmaceutical Research Division, Takeda Pharmaceutical Company Limited, 26-1 Muraoka-Higashi 2-chome, Fujisawa, Kanagawa 251-8555, Japan

E-mail: yukimasa.makita@takeda.com

Key words: patient-derived tumor xenograft, kinetochore-associated protein 2, short interfering RNA, lipid nanoparticle, lung cancer, three-dimensional culture, erlotinib tumor tissues derived from patients with cancer in the flank of immuno-deficient mice $(3,4)$. Compared with conventional cancer cell lines, PDXs have been reported to be more relevant to the original tumor tissues of patients with cancer in terms of drug sensitivity, heterogeneity and genetic status (5-9). Accordingly, PDXs may be used for the evaluation of new anticancer drugs (10).

Lung cancer is categorized into small cell lung cancer (SCLC) and non-small cell lung cancer (NSCLC). The most common types of NSCLC are squamous cell carcinoma, adenocarcinoma and large cell carcinoma (11). These types of NSCLC are further classified into several stages according to their disease status (12). Several anticancer drugs have been developed for each type of lung cancer. Their molecular targets include epidermal growth factor receptor (EGFR) tyrosine kinase [erlotinib (13), gefitinib (14) and afatinib (15)], rearranged anaplastic lymphoma kinase [crizotinib (16), ceritinib (17) and alectinib (18)], folate-dependent enzymes [pemetrexed (19)], vascular endothelial growth factor [bevacizumab (20)], C-X-C chemokine receptor type 4 [LY2510924 (21)] and programmed cell death protein 1 [nivolumab (22)]. Although these drugs demonstrated therapeutic effects in patients with several types of lung cancer, novel drugs targeting underlying molecular mechanisms are required in order to progress therapeutic approaches to lung cancer.

Kinetochore-associated protein 2 (KNTC2), also known as highly expressed in cancer 1 , serves an important function in the segregation of chromosomes during M phase (23). KNTC2 is upregulated in tumor tissues of cancer patients and has been identified as a potential target for cancer therapy (24). Antitumor activities of KNTC2 short interfering (si)RNA have previously been demonstrated in vivo in orthotopic hepatocellular carcinoma tumor mouse models (25). However, it remains unclear whether KNTC2 siRNA exhibits antitumor activities against lung cancer PDXs.

To clarify the involvement of KNTC2 in the growth of lung cancer PDXs, KNTC2 siRNA was encapsulated into a lipid nanoparticle (KNTC2-LNP) and the growth inhibiting activities of KNTC2-LNP were evaluated in a three-dimensional (3D)-culture system and subcutaneous tumor models of lung cancer PDXs; LC-60 (resistant to erlotinib) and LC-45 (sensitive to erlotinib). 


\section{Materials and methods}

Lung cancer PDXs. Lung cancer PDXs, LC-45 (adenocarcinoma) and LC-60 (small or large cell carcinoma) were purchased from the Central Institute for Experimental Animals (Kanagawa, Japan). PDXs were maintained in the flank of 20 (LC-45) or 15 (LC-60) BALB/c nude mice (20-25 g; 7-8 weeks old; female; Charles River Laboratories International, Inc., Kanagawa, Japan). When PDXs grew to $\sim 1,000 \mathrm{~mm}^{3}$, PDXs were excised and cryopreserved in small pieces (40-70 $\mu \mathrm{m}$ ) using Cell Banker 2 (Nippon Zenyaku Kogyo, Co., Ltd., Fukushima, Japan). Humane endpoint was determined by $20 \%$ weight loss and the maximum tumor size was 2,000 $\mathrm{mm}^{3}$. Mice were maintained in specific pathogen-free conditions with free access to food and water, under a constant temperature of $22 \pm 2^{\circ} \mathrm{C}$ and a $12 / 12 \mathrm{~h}$ light/dark cycle. All experiments were approved by the Institutional Animal Care and Use Committee in Takeda Pharmaceutical Company Limited (Fujisawa, Japan; approval number 11387).

Chemical modification of siRNAs. KNTC2 siRNA and Luc siRNA (26) (negative control) were synthesized by GeneDesign (Osaka, Japan) and chemically modified with 2'- $O$-methyl ribonucleotide to prevent immune responses, as described previously (27). Phosphorothioate (PS) modifications were not used in KNTC2 siRNA because they generate optical isomers. The sequences and chemical modifications are presented in Table I.

Encapsulation of siRNAs into a lipid nanoparticle. KNTC2 siRNA or Luc siRNA $(200 \mu \mathrm{g} / \mathrm{ml}$, total $8 \mathrm{mg})$ was encapsulated into a lipid nanoparticle (LNP) using a microfluidic device, Asia (model no. 210; Syrris, Royston, UK). Each LNP was composed of 3-((5-(dimethylamino) pentanoyl)oxy)-2,2-bis(((3-pentyloctanoyl)oxy)methyl)propyl 3-pentyloctanoate (28), dipalmitoylphosphatidylcholine (NOF Corporation, Tokyo, Japan), cholesterol (Avanti Polar Lipids, Inc., Alabaster, Alabama) and GS-020 (NOF Corporation) at the molar ratio of 60, 10.6, 28 and 1.4, respectively. Particle size and polydispersity index (PdI) of LNPs were measured by dynamic light scattering using a Zetasizer Nano ZS (Malvern Instruments Ltd., Malvern, UK). The ratio of siRNA entrapment was calculated using Ribogreen (Thermo Fisher Scientific, Inc., Waltham, MA) and Triton X-100 as described previously (29). Briefly, LNPs were dissolved in 1\% Triton X-100 to release the siRNAs. The concentrations of siRNA prior to and following the dissolution were calculated by applying Ribogreen (29) at a final concentration of $0.25 \%$ and measuring the fluorescence of Ribogreen using a spectrofluorometer, Envision (Excitation, $485 \mathrm{~nm}$ and Emission, $535 \mathrm{~nm}$ ) and Envision software (version 1.13.3009.1409, PerkinElmer, Inc., Waltham, MA, USA).

Evaluation of knockdown activities in subcutaneous tumor models of PDXs. Small pieces $\left(\sim 100 \mathrm{~mm}^{3}\right)$ of PDXs were inoculated in the flank of BALB/c nude mice using a trocar needle (KN-391; Natsume Seisakusho, Co., Ltd., Tokyo, Japan). Tumor sizes were measured with calipers and defined as major axis $x$ minor axis $2 / 2$, as previously described (9). When the tumor sizes reached between 100 and $400 \mathrm{~mm}^{3}, 9$ mice were selected from a total of 20 mice and divided into three groups (PBS, KNTC2 and Luc) using EXSUS 2014 software (CAC Exicare Corporation, Tokyo, Japan). KNTC2 siRNA encapsulated into LNP (KNTC2-LNP) was intravenously administered at $5 \mathrm{mg} / \mathrm{kg}(\mathrm{n}=3)$. Luc siRNA-LNP was used as the negative control. PBS was administered to the vehicle control group. Knockdown activity was measured 3 days after the single administration. Total RNA was extracted from tumor tissue using TRIzol ${ }^{\circledR}$ (Life Technologies; Thermo Fisher Scientific, Inc.) and reverse transcribed (thermocycling conditions: $25^{\circ} \mathrm{C}$ for $10 \mathrm{~min} ; 42^{\circ} \mathrm{C}$ for $1 \mathrm{~h}$; and $85^{\circ} \mathrm{C}$ for $5 \mathrm{~min}$ ) using SuperScript VILO cDNA Synthesis kit (Thermo Fisher Scientific, Inc.). The copy numbers of human KNTC2, human $\beta$-actin $(A C T B)$, mouse $K n t c 2$ and mouse $A c t b$ mRNA were individually measured by quantitative polymerase chain reaction using a Real-Time PCR System (Thermo Fisher Scientific, Inc.). Species-specific qPCR primers and probes (Thermo Fisher Scientific, Inc.) are listed in Table II. Copy numbers of $K N T C 2$ or $K n t c 2$ mRNA were individually normalized to $A C T B$ or $A c t b$ mRNA.

Evaluation of growth inhibitory activities in subcutaneous tumor models of PDXs. A total of 10 or 15 mice were selected from 20 or 45 mice (total number of mice, 65), respectively, and divided into two (control and erlotinib) or three (control, KNTC2 and Luc) groups using EXSUS 2014 software. Erlotinib (Carbosynth, Ltd., Compton, UK) was orally administered at $100 \mathrm{mg} / \mathrm{kg}$ once a day for 11 days (LC-45) or 5 days (LC-60). In addition, $0.5 \%$ methylcellulose was used as the control $(n=5)$. KNTC2-LNP was intravenously administered at $5 \mathrm{mg} / \mathrm{kg}$ at three time points, with three days between each administration. Luc siRNA-LNP was used as the negative control. PBS was administered to the vehicle control group. Tumor sizes were measured as aforementioned. Growth inhibitory rate (\%) was calculated using the formula: (1-tumor growth of treated group/tumor growth of untreated group) x $100 \%$ (9).

Cryopreservation of PDXs for $3 D$ culture systems. PDXs were excised from BALB/c nude mice and cut into small pieces $\left(\sim 100 \mathrm{~mm}^{3}\right)$. These pieces were digested in Dulbecco's modified eagle's medium (DMEM) high glucose (Thermo Fisher Scientific, Inc.) containing $75 \mathrm{U} / \mathrm{ml}$ collagenase type XI (Sigma-Aldrich; Merck KGaA, Darmstadt, Germany), $125 \mu \mathrm{g} / \mathrm{ml}$ dispase type II (Thermo Fisher Scientific, Inc.), $2.5 \%(\mathrm{v} / \mathrm{v})$ fetal bovine serum (Thermo Fisher Scientific, Inc.) and $100 \mathrm{U} / \mathrm{ml}$ penicillin/streptomycin at $37^{\circ} \mathrm{C}$. Digestion was terminated prior to complete dispersion of the PDXs. PDXs of intermediate size (between 40 and $100 \mu \mathrm{m}$ ) were collected using a cell strainer and cryopreserved in a Cell Banker 2 (Nippon Zenyaku Kogyo, Co., Ltd.) at $-160^{\circ} \mathrm{C}$.

3D-culture of cryopreserved PDXs. Cryopreserved PDXs were suspended in Advanced DMEM/F12 (ratio, 1:1; Thermo Fisher Scientific, Inc.) containing $10 \mathrm{mM}$ 4-(2-hydroxyethyl)-1-piperazineethanesulfonic acid, $2 \mathrm{mM}$ GlutaMAX-1 (Thermo Fisher Scientific, Inc.), N2 supplement (Thermo Fisher Scientific, Inc.), B27 supplement (Thermo Fisher Scientific, Inc.), $100 \mathrm{U} / \mathrm{ml}$ penicillin/streptomycin, $1 \mathrm{mM}$ N-acetylcysteine, $500 \mathrm{nM}$ A-83-01 and $1 \mu \mathrm{M}$ SB202190 
Table I. List of chemically modified siRNAs.

\begin{tabular}{|c|c|c|}
\hline siRNA & Strand & Sequence \\
\hline \multirow[t]{2}{*}{ Luc siRNA } & Sense & 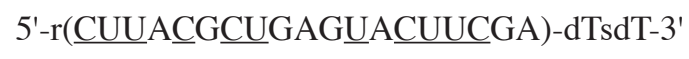 \\
\hline & Antisense & 5'-r(UCGAAG $\underline{U} A C U \underline{C} A G C G \underline{U} A A G)-d T s d T-3 '$ \\
\hline \multirow[t]{2}{*}{ KNTC2 siRNA } & Sense & 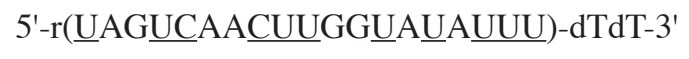 \\
\hline & Antisense & 5'-r(AAA $\underline{U} A \underline{U} A C \underline{C A A G U U G A C \underline{U} A)-d T d T-3^{\prime}}$ \\
\hline
\end{tabular}

siRNA, shortinterfering RNA;r,ribonucleotide; d,deoxy-ribonucleotide; s,phosphorothioate modification; underline,2'- $O$-methyl ribonucleotide.

Table II. List of species specific quantitative polymerase chain reaction primers and probes.

\begin{tabular}{|c|c|}
\hline Gene & Sequence $\left(5^{\prime}-3^{\prime}\right)$ \\
\hline \multicolumn{2}{|c|}{ Human $K N T C 2$} \\
\hline Forward & $\begin{array}{l}\text { GAGGTACATAAACTTGAGCCCT } \\
\text { GTATT }\end{array}$ \\
\hline Reverse & $\begin{array}{l}\text { TGCTGAGAATTCCAAAGGTTAT } \\
\text { GA }\end{array}$ \\
\hline Probe & $\begin{array}{l}\text { TGGCACCAGCCTCGGGATTAAA } \\
\text { CTTAA }\end{array}$ \\
\hline \multicolumn{2}{|c|}{ Human $A C T B$} \\
\hline Forward & CCTGGCACCCAGCACAAT \\
\hline Reverse & GCCGATCCACACGGAGTA CT \\
\hline Probe & $\begin{array}{l}\text { ATCAAGATCATTGCTCCTCCTG } \\
\text { AGCGC }\end{array}$ \\
\hline \multicolumn{2}{|c|}{ Mouse Kntc2 } \\
\hline Forward & $\begin{array}{l}\text { GAATAAAAAGAGGCATCTGGAG } \\
\text { GATAC }\end{array}$ \\
\hline Reverse & ССТCCTTCAGCATCCTCACAGT \\
\hline Probe & $\begin{array}{l}\text { CAACTGAACACCATGAAAACG } \\
\text { GAAAGCAA }\end{array}$ \\
\hline \multicolumn{2}{|c|}{ Mouse $A c t b$} \\
\hline Forward & CACTATTGGCAACGAGC GG) \\
\hline Reverse & TCCATACCCAAGAAGGAAGGC \\
\hline Probe & $\begin{array}{l}\text { TCCGATGCCCTGAGGCTCTTT } \\
\text { TCC }\end{array}$ \\
\hline
\end{tabular}

KNTC2, kinetochore-associated protein 2 ; ACTB, $\beta$-actin.

as previously described (30). Subsequently, PDXs were seeded in U-bottom 96-well plate (Sumitomo Bakelite Co., Ltd., Tokyo, Japan) and cultured in a $5 \% \mathrm{CO}_{2}$-humidified chamber at $37^{\circ} \mathrm{C}$. Growth of PDX was monitored using Cellavista and Cellavista Control and Evaluation Software version 2.1.0.876 (Synentec GmbH, Elmshorn, Germany). Data was omitted when the shape of PDX was not recognized by Cellavista.

Evaluation of knockdown activities in 3D-culture system of PDXs. PDXs were cultured for four days as aforementioned. KNTC2-LNP was added at concentrations of
$10,100 \mathrm{nM}$ and $1 \mu \mathrm{M}(\mathrm{n}=6)$. PDXs were subsequently cultured for an additional three days and mixed together due to each tumor volume being too small to obtain a sufficient amount of total RNA for evaluating knockdown activities. Total RNA was extracted using RNeasy kit (Qiagen $\mathrm{GmbH}$, Hilden, Germany) and reverse-transcribed using SuperScript VILO cDNA Synthesis kit, according to manufacturer's protocols. Knockdown activities were calculated as aforementioned.

Evaluation of growth inhibitory activities in a 3D-culture system of PDXs. PDXs were cultured for three (LC-60) or four (LC-45) days as aforementioned $(n=6)$. KNTC2-LNP was added at concentrations ranging from $10,100 \mathrm{nM}$ and $1 \mu \mathrm{M}$. Erlotinib (Carbosynth) was added at concentrations of $10,100 \mathrm{nM}, 1$ and $10 \mu \mathrm{M}$ using a sample-dispensing machine (HP D300 Digital Dispenser, Tecan Japan Co., Ltd., Kawasaki, Japan). Growth inhibitory rate was calculated using the formula as aforementioned.

Statistical analysis. Data was statistically analyzed using EXSUS 2014 software (CAC Exicare Corporation). Significance among groups was analyzed using Bartlett's test followed by Dunnett's test (in vivo studies) or Williams' test (in vitro studies). $\mathrm{P}<0.05$ was considered to indicate a statistically significant difference.

\section{Results}

Sensitivities of lung cancer PDXs to erlotinib. To select different types of lung cancer PDXs for the evaluation of KNTC2-LNP, the sensitivities of several PDXs to erlotinib (an approved drug for patients with lung cancer) were investigated. Among those PDXs, LC-45 exhibited relatively high sensitivity to erlotinib in a subcutaneous tumor model (Fig. 1A). Repeated oral administration of erlotinib $(100 \mathrm{mg} / \mathrm{kg}$, once a day) significantly $(\mathrm{P}<0.001)$ inhibited the tumor growth of LC- 45 by $86 \%$. In contrast, the same dosage of erlotinib did not inhibit the tumor growth of LC-60 (Fig. 1B).

Sensitivities of LC-45 and LC-60 to erlotinib were also investigated in 3D-culture systems. Erlotinib significantly $(\mathrm{P}<0.001)$ inhibited the growth of LC- 45 by $81 \%$ at the concentration of $1 \mu \mathrm{M}$ (Fig. 2A). The growth of LC-60 was not inhibited by erlotinib at the same concentration indicating that LC-60 was less sensitive to erlotinib compared with LC-45 (Fig. 2B). 

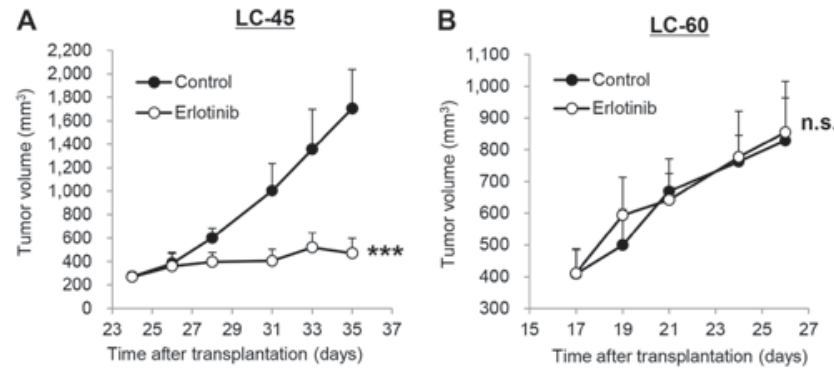

Figure 1. Sensitivities of lung cancer patient-derived tumor xenografts to erlotinib in subcutaneous tumor models. Patient-derived xenografts (A) LC-45 and (B) LC-60 were inoculated in the flank of BALB/c nude mice. Erlotinib $(100 \mathrm{mg} / \mathrm{kg})$ was orally administered once a day during the test periods. Control group mice were treated with $0.5 \%$ methylcellulose. Values are presented as the mean + standard deviation $(n=5) .{ }^{* * *} \mathrm{P}<0.001$ vs. control using Dunnett's test. n.s., no significance.
A

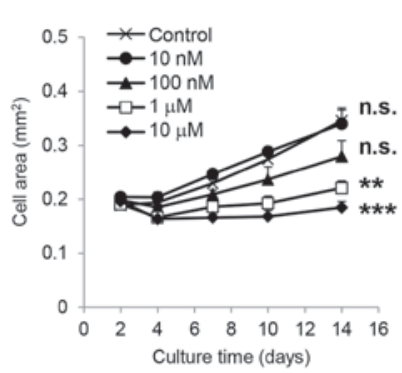

B $\quad \underline{L C-60}$

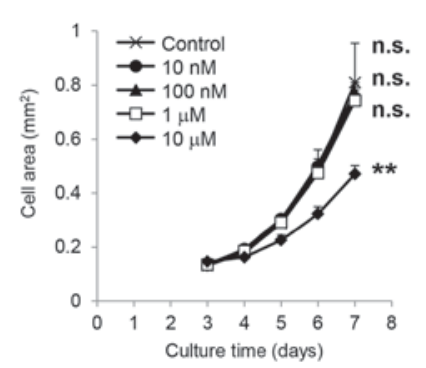

Figure 2. Sensitivities of lung cancer patient-derived tumor xenografts to erlotinib in 3D-culture systems. Growth inhibitory activities of erlotinib were evaluated in 3D-culture systems of (A) LC-45 and (B) LC-60. The concentrations of erlotinib were $10,100 \mathrm{nM}, 1$ and $10 \mu \mathrm{M}$. Values are presented as the mean + the standard error of the mean $(n=4)$. ${ }^{* *} \mathrm{P}<0.005,{ }^{* * *} \mathrm{P}<0.0005$ compared with control, using Williams' test. n.s., no significance; 3D, 3 dimensional.

Encapsulation of siRNAs into LNP. The particle sizes of KNTC2 siRNA-LNP and Luc siRNA-LNP were 75 and $73 \mathrm{~nm}$, respectively. PdIs were 0.012 and 0.022 . The entrapment efficiencies were 98.2 and $97.6 \%$, demonstrating that each siRNA was successfully encapsulated into LNP.

Knockdown and growth inhibitory activities of KNTC2-LNP in $3 D$-culture systems of $L C$ - 60 . The knockdown activities of KNTC2-LNP were $60 \%$ at $10 \mathrm{nM}, 79 \%$ at $100 \mathrm{nM}$ and $88 \%$ at $1 \mu \mathrm{M}$ in 3D-culture systems of LC-60 (Fig. 3A). The knockdown activities of Luc siRNA-LNP (negative control) were markedly decreased compared with KNTC2-LNP, indicating the specificity of KNTC2 siRNA (Fig. 3B).

Tumor growth of LC-60 was significantly inhibited by KNTC2-LNP at $100 \mathrm{nM}$ and $1 \mu \mathrm{M}(\mathrm{P}<0.001$; Fig. 4A). The growth inhibition rates were 21 and $63 \%$, respectively. Luc siRNA-LNP (negative control) did not significantly inhibit the growth of LC-60 at the same concentrations, indicating that growth inhibition was specifically caused by the suppression of human KNTC2 mRNA expression (Fig. 4B).

Knockdown and growth inhibitory activities of KNTC2-LNP in subcutaneous tumor models of lung cancer PDXs.
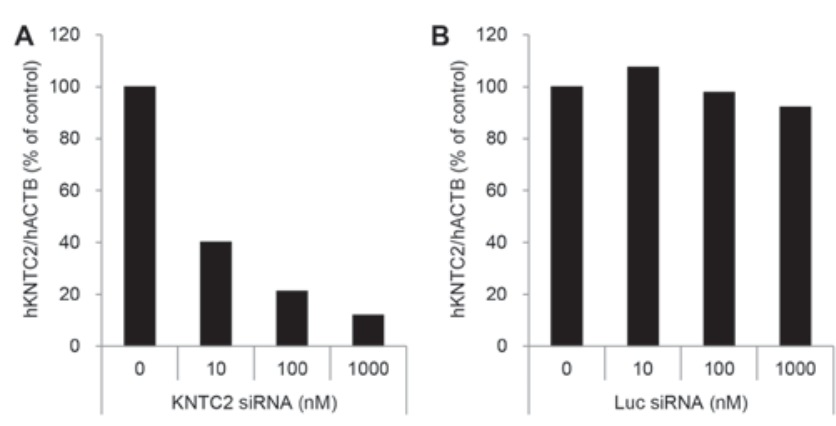

Figure 3. Knockdown activities of KNTC2-LNP in 3D-culture system of LC-60. The knockdown activity of KNTC2-LNP $(10 \mathrm{nM}-1 \mu \mathrm{M})$ was evaluated in a 3D-culture system of (A) LC-60. (B) Luc siRNA-LNP was used as a negative control. The expression levels of human KNTC2 mRNAs were measured three days after the addition of lipid nanoparticles $(n=6)$. hKNTC2, human kinetochore-associated protein 2 ; 3D, 3 dimensional; ACTB, $\beta$-actin; siRNA, short interfering RNA.
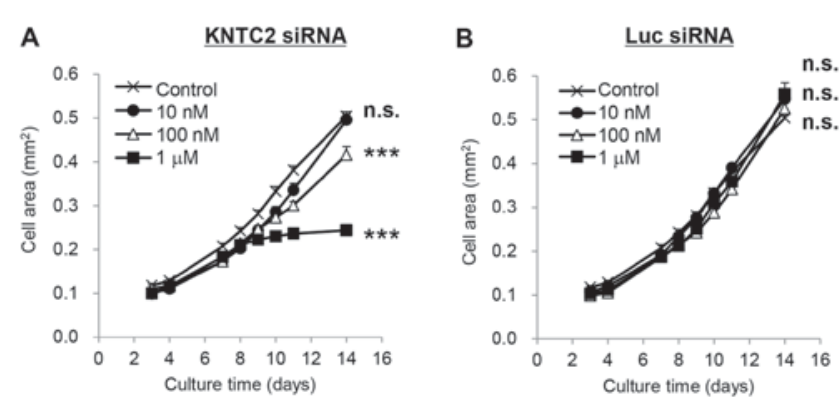

Figure 4. Growth inhibitory activity of KNTC2-LNP in 3D-culture system of LC-60. (A) Growth inhibitory activity of KNTC2-LNP was evaluated in 3D-culture systems of LC-60. (B) Luc siRNA-LNP was used as a negative control. These siRNAs were evaluated at $10,100 \mathrm{nM}$ and $1 \mu \mathrm{M}$. Values are presented as the mean + the standard error of the mean $(n=5$ or 6$) .{ }^{* * *} \mathrm{P}<0.0005$ vs. control, using Williams' test. n.s., no significance; 3D, 3 dimensional; KNTC2, kinetochore-associated protein 2; siRNA, short interfering RNA.

Knockdown and growth inhibitory activities of KNTC2-LNP were further investigated in the subcutaneous tumor model of LC-60. Single intravenous administration of KNTC2-LNP $(5 \mathrm{mg} / \mathrm{kg})$ significantly suppressed the expression levels of human KNTC 2 and mouse Kntc2 mRNA in LC-60 by 27 and $46 \%$, respectively $(\mathrm{P}<0.01$; Fig. $5 \mathrm{~A}$ and B). Luc siRNA-LNP (negative control) did not exhibit knockdown activities at the same dosage. Repeated intravenous administration of KNTC2-LNP ( $5 \mathrm{mg} / \mathrm{kg}$, twice a week) significantly inhibited the growth of LC-60 by $67 \%(\mathrm{P}<0.001$; Fig. 5C). Luc siRNA-LNP did not inhibit the growth of LC-60 indicating that the growth inhibition was specifically caused by the suppression of human KNTC2 and mouse Kntc2 mRNA expression levels.

Knockdown and growth inhibitory activities of KNTC2-LNP were also investigated using another lung cancer PDX, LC-45. Single intravenous administration of KNTC2-LNP $(5 \mathrm{mg} / \mathrm{kg})$ significantly suppressed the expression levels of human KNTC2 and mouse Kntc 2 mRNA in LC- 45 by 63 and 60\%, respectively $(\mathrm{P}<0.001$; Fig. 6A and B). Repeated intravenous administration of KNTC2-LNP $(5 \mathrm{mg} / \mathrm{kg}$, twice a week) significantly inhibited the growth of LC- 45 by $63 \%(\mathrm{P}<0.01$; Fig. $6 \mathrm{C})$ suggesting that KNTC2-LNP exhibits antitumor activity against various types of lung cancer PDXs. 

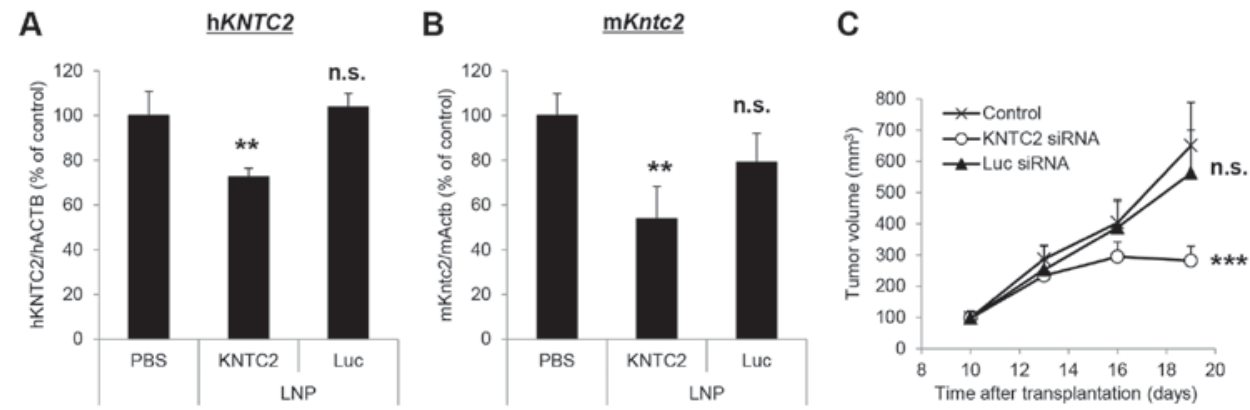

Figure 5. Knockdown and growth inhibitory activities of KNTC2-LNP in a subcutaneous tumor model of LC-60. Knockdown activities of KNTC2-LNP $(5 \mathrm{mg} / \mathrm{kg}$ ) were evaluated three days following a single intravenous administration. PBS and Luc siRNA-LNP were used as controls. The expression levels of (A) human KNTC2 mRNA and (B) mouse Kntc2 mRNA were investigated. Values are presented as the mean + the standard deviation (n=3). (C) Growth inhibitory activities of KNTC2-LNP $(5 \mathrm{mg} / \mathrm{kg})$ were evaluated during repeated intravenous administration (twice a week). Values are presented as the mean + the standard deviation $(\mathrm{n}=5) .{ }^{* *} \mathrm{P}<0.01$ vs. $\mathrm{PBS} ;{ }^{* * * *} \mathrm{P}<0.001$ vs. control using Dunnett's test. KNTC2, kinetochore-associated protein 2; n.s., no significance; LNP, lipid nanoparticle; ACTB, $\beta$-actin; siRNA, short interfering RNA.
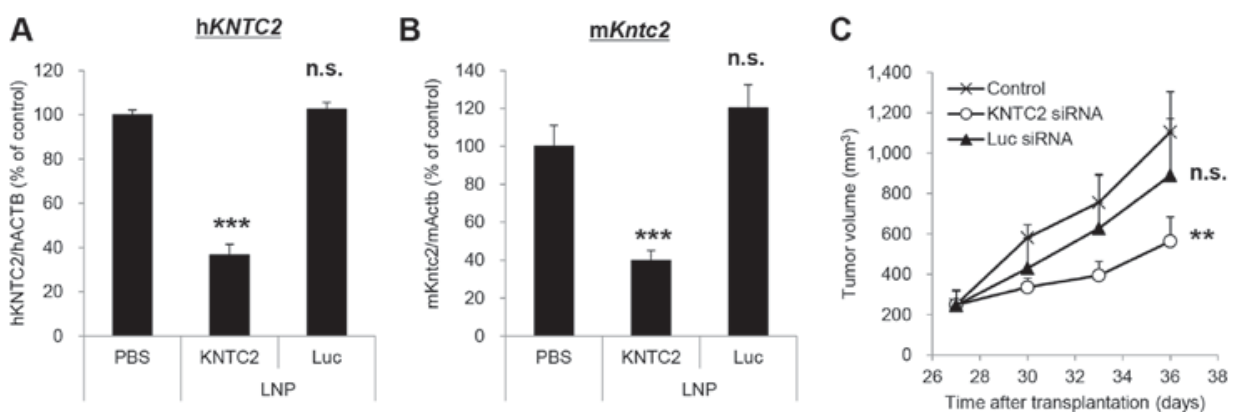

Figure 6. Knockdown and growth inhibitory activities of KNTC2-LNP in a subcutaneous tumor model of LC-45. Knockdown activities of KNTC2-LNP $(5 \mathrm{mg} / \mathrm{kg})$ were evaluated three days following a single intravenous administration. PBS and Luc siRNA-LNP were used as controls. The expression levels of (A) human KNTC2 mRNA and (B) mouse Kntc2 mRNA were investigated. Values are presented as the mean + the standard deviation (n=3). (C) Growth inhibitory activities of KNTC2-LNP $(5 \mathrm{mg} / \mathrm{kg})$ were evaluated during repeated intravenous administration (twice a week). Values are presented as the mean + the standard deviation $(\mathrm{n}=5) .{ }^{* *} \mathrm{P}<0.01$, vs. control; ${ }^{* * *} \mathrm{P}<0.001$ vs. control using Dunnett's test. KNTC2, kinetochore-associated protein 2; LNP, lipid nanoparticle; ACTB, $\beta$-actin; n.s., no significance; siRNA, short interfering RNA.

\section{Discussion}

To clarify the involvement of KNTC2 in the growth of lung cancer PDXs, the growth inhibitory activities of KNTC2-LNP were evaluated in 3D-culture systems and subcutaneous tumor models of lung cancer PDXs, LC-45 and LC-60.

Lung cancer PDXs implanted into the flank of immuno-deficient mice were estimated to be composed of lung cancer patient-derived human cells and host mouse-derived stromal cells (31). Stromal cells have been reported to affect the proliferation of cancer cells in tumor tissues (32). Therefore, in the present study, KNTC2 siRNA that suppressed not only human $K N T C 2$ mRNA but also mouse Kntc2 mRNA was selected in order to clarify the involvement of KNTC2 in human-derived cancer cells and mouse-derived stromal cells. The knockdown activities of KNTC2 siRNA were sufficient to inhibit the in vivo growth of LC-60 and LC-45. Negative control Luc siRNA did not inhibit the growth of these PDXs, indicating that their growths were dependent on KNTC2.

Notably, KNTC2 siRNA inhibited the growth of LC-60 that was resistant to an approved drug, erlotinib. According to previous studies, KNTC2 siRNA was estimated to impair the chromosome segregation of LC-60 leading to cell cycle arrest and apoptosis $(33,34)$. This molecular mechanism is distinct from that of erlotinib, which inhibits the auto-phosphorylation of EGFR tyrosine kinase (35). Inhibitors of EGFR tyrosine kinase were reported to be ineffective in patients with lung cancer with mutations in KRAS (36) or EGFR (37). LC-60 exhibited a mutated KRAS gene (G12V). Therefore, KNTC2 may be a therapeutic target for patients with lung cancer that is resistant to erlotinib.

Several types of 3D-culture systems have been developed for PDXs to increase the efficiency of drug screening (38-40). Efficiency of evaluating KNTC2 siRNA was increased by establishing 3D-culture systems of LC-45 and LC-60. Their sensitivities to erlotinib were similar to that of subcutaneous tumors. These results were consistent with previous reports demonstrating the similarities of 3D-culture systems to subcutaneous tumor models using other lung cancer PDXs $(41,42)$.

The maximum knockdown activity of KNTC2-LNP in the 3D-culture system was sufficient to inhibit the growth of LC-60 and predict the result of in vivo study. In contrast, growth inhibitory activity of KNTC2-LNP was not detected in the 3D-culture system of LC-45 (data not shown). The reason for these results was speculated to be that the maximum knockdown activity of KNTC2-LNP was insufficient to inhibit the growth of LC-45. Applicability of the 3D-culture system to the evaluation of KNTC2-LNP was considered to be different between PDXs. 
In conclusion, the involvement of KNTC2 in the growth of lung cancer PDXs LC-45 (sensitive to erlotinib) and LC-60 (resistant to erlotinib) was clarified. The results markedly indicated that KNTC2 is a promising target for the treatment of lung cancer.

\section{Acknowledgements}

The authors wish to thank Dr Keiji Yamamoto, Dr Kazuhiro Ogi, Dr Michiyasu Takeyama, Dr Hirokazu Matsumoto and Dr Toshiyuki Nomura for encouraging the accomplishment of this work. The authors also thank Dr Tadahiro Nambu, Mr Yuji Baba, Dr Kazuhide Nakamura and Dr Toshiya Tamura for the helpful discussion to establish 3D culture systems of PDXs, Dr Rumiko Ochiai for helpful discussion on the formulation of lipid nanoparticles and Ms Syu Morita and Ms Kaori Konno for technical assistance. KNTC2 siRNAs were designed and selected by Dr Nobuyuki Miyajima, Mr Yoshiki Katou, Ms Kuniko Kikuchi and Dr Hiroshi Uejima. All of the aforementioned individuals were affiliated to Takeda Pharmaceutical Company, Ltd., Kanagawa, Japan at the time when the present study was undertaken.

\section{References}

1. Tentler JJ, Tan AC, Weekes CD, Jimeno A, Leong S, Pitts TM Arcaroli JJ, Messersmith WA and Eckhardt SG: Patient-derived tumour xenografts as models for oncology drug development. Nat Rev Clin Oncol 9: 338-350, 2012.

2. Pompili L, Porru M, Caruso C, Biroccio A and Leonetti C: Patient-derived xenografts: A relevant preclinical model for drug development. J Exp Clin Cancer Res 35: 189, 2016.

3. Fichtner I, Rolff J, Soong R, Hoffmann J, Hammer S, Sommer A, Becker $\mathrm{M}$ and Merk J: Establishment of patient-derived non-small cell lung cancer xenografts as models for the identification of predictive biomarkers. Clin Cancer Res 14: 6456-6468, 2008.

4. Wang D, Pham NA, Tong J, Sakashita S, Allo G, Kim L, Yanagawa N, Raghavan V, Wei Y, To C, et al: Molecular heterogeneity of non-small cell lung carcinoma patient-derived xenografts closely reflect their primary tumors. Int J Cancer 140: 662-673, 2017.

5. Perez-Soler R, Kemp B, Wu QP, Mao L, Gomez J, Zeleniuch-Jacquotte A, Yee H, Lee JS, Jagirdar J and Ling YH: Response and determinants of sensitivity to paclitaxel in human non-small cell lung cancer tumors heterotransplanted in nude mice. Clin Cancer Res 6: 4932-4938, 2000.

6. Daniel VC, Marchionni L, Hierman JS, Rhodes JT, Devereux WL, Rudin CM, Yung R, Parmigiani G, Dorsch M, Peacock CD and Watkins DN: A primary xenograft model of small-cell lung cancer reveals irreversible changes in gene expression imposed by culture in vitro. Cancer Res 69: 3364-3373, 2009.

7. Zhang XC, Zhang J, Li M, Huang XS, Yang XN, Zhong WZ, Xie L, Zhang L, Zhou M, Gavine P, et al: Establishment of patient-derived non-small cell lung cancer xenograft models with genetic aberrations within EGFR, KRAS and FGFR1: Useful tools for preclinical studies of targeted therapies. J Transl Med 11: 168, 2013

8. Ilie M, Nunes M, Blot L, Hofman V, Long-Mira E, Butori C, Selva E, Merino-Trigo A, Vénissac N, Mouroux J, et al: Setting up a wide panel of patient-derived tumor xenografts of non-small cell lung cancer by improving the preanalytical steps. Cancer Med 4: 201-211, 2015.

9. Owonikoko TK, Zhang G, Kim HS, Stinson RM, Bechara R, Zhang C, Chen Z, Saba NF, Pakkala S, Pillai R, et al: Patient-derived xenografts faithfully replicated clinical outcome in a phase II co-clinical trial of arsenic trioxide in relapsed small cell lung cancer. J Transl Med 14: 111, 2016.

10. Nukatsuka M, Saito H, Nakagawa F, Tsujimoto H, Sakamoto K, Tsukioka S, Uchida J, Kiniwa M, Kobunai T and Takechi T: Combination therapy using oral S-1 and targeted agents against human tumor xenografts in nude mice. Exp Ther Med 3: 755-762, 2012.
11. Hu Y, Wang $\mathrm{L}, \mathrm{Gu} \mathrm{J}, \mathrm{Qu} \mathrm{K}$ and Wang Y: Identification of microRNA differentially expressed in three subtypes of non-small cell lung cancer and in silico functional analysis. Oncotarget 8: 74554-74566, 2017.

12. Nicholson AG, Chansky K, Crowley J, Beyruti R, Kubota K, Turrisi A, Eberhardt WE, van Meerbeeck J and Rami-Porta R; Staging and Prognostic Factors Committee, Advisory Boards, and Participating Institutions; Staging and Prognostic Factors Committee Advisory Boards and Participating Institutions: The international association for the study of lung cancer lung cancer staging project: Proposals for the revision of the clinical and pathologic staging of small cell lung cancer in the forthcoming Eighth edition of the TNM classification for lung cancer. J Thorac Oncol 11: 300-311, 2016.

13. Johnson JR, Cohen M, Sridhara R, Chen YF, Williams GM, Duan J, Gobburu J, Booth B, Benson K, Leighton J, et al: Approval summary for erlotinib for treatment of patients with locally advanced or metastatic non-small cell lung cancer after failure of at least one prior chemotherapy regimen. Clin Cancer Res 11: 6414-6421, 2005.

14. Sequist LV, Martins RG, Spigel D, Grunberg SM, Spira A, Jänne PA, Joshi VA, McCollum D, Evans TL, Muzikansky A, et al: First-line gefitinib in patients with advanced non-small-cell lung cancer harboring somatic EGFR mutations. J Clin Oncol 26: 2442-2449, 2008 .

15. Dungo RT and Keating GM: Afatinib: First global approval. Drugs 73: 1503-1515, 2013.

16. Malik SM, Maher VE, Bijwaard KE, Becker RL, Zhang L, Tang SW, Song P, Liu Q, Marathe A, Gehrke B, et al: U.S. food and drug administration approval: Crizotinib for treatment of advanced or metastatic non-small cell lung cancer that is anaplastic lymphoma kinase positive. Clin Cancer Res 20: 2029-2034, 2014

17. Kim DW, Mehra R, Tan DS, Felip E, Chow LQ, Camidge DR, Vansteenkiste J, Sharma S, De Pas T, Riely GJ, et al: Activity and safety of ceritinib in patients with ALK-rearranged non-small-cell lung cancer (ASCEND-1): Updated results from the multicentre, open-label, phase 1 trial. Lancet Oncol 17: 452-463, 2016.

18. Song Z, Wang $\mathrm{M}$ and Zhang A: Alectinib: A novel second generation anaplastic lymphoma kinase (ALK) inhibitor for overcoming clinically-acquired resistance. Acta Pharm Sin B 5: 34-37, 2015.

19. Hazarika M, White RM, Johnson JR and Pazdur R: FDA drug approval summaries: Pemetrexed (Alimta). Oncologist 9: 482-488, 2004

20. Cohen MH, Gootenberg J, Keegan P and Pazdur R: FDA drug approval summary: Bevacizumab (Avastin) plus Carboplatin and Paclitaxel as first-line treatment of advanced/metastatic recurrent nonsquamous non-small cell lung cancer. Oncologist 12: 713-718, 2007.

21. Salgia R, Stille JR, Weaver RW, McCleod M, Hamid O, Polzer J, Roberson S, Flynt A and Spigel DR: A randomized phase II study of LY2510924 and carboplatin/etoposide versus carboplatin/etoposide in extensive-disease small cell lung cancer. Lung Cancer 105: 7-13, 2017.

22. Brahmer J, Reckamp KL, Baas P, Crinò L, Eberhardt WE, Poddubskaya E, Antonia S, Pluzanski A, Vokes EE, Holgado E, et al: Nivolumab versus docetaxel in advanced Squamous-cell Non-small-cell lung cancer. N Engl J Med 373: 123-135, 2015.

23. Chen Y, Riley DJ, Chen PL and Lee WH: HEC, a novel nuclear protein rich in leucine heptad repeats specifically involved in mitosis. Mol Cell Biol 17: 6049-6056, 1997.

24. Ferretti C, Totta P, Fiore M, Mattiuzzo M, Schillaci T, Ricordy R, Di Leonardo A and Degrassi F: Expression of the kinetochore protein Hecl during the cell cycle in normal and cancer cells and its regulation by the $\mathrm{pRb}$ pathway. Cell Cycle 9: 4174-4182, 2010.

25. Makita Y, Murata S, Katou Y, Kikuchi K, Uejima H, Teratani M, Hoashi Y, Kenjo E, Matsumoto S, Nogami M, et al: Anti-tumor activity of KNTC2 siRNA in orthotopic tumor model mice of hepatocellular carcinoma. Biochem Biophys Res Commun 493: 800-806, 2017.

26. Elbashir SM, Harborth J, Lendeckel W, Yalcin A, Weber K and Tuschl T: Duplexes of 21-nucleotide RNAs mediate RNA interference in cultured mammalian cells. Nature 411: 494-498, 2001.

27. Frank-Kamenetsky M, Grefhorst A, Anderson NN, Racie TS, Bramlage B, Akinc A, Butler D, Charisse K, Dorkin R, Fan Y, et al: Therapeutic RNAi targeting PCSK9 acutely lowers plasma cholesterol in rodents and LDL cholesterol in nonhuman primates. Proc Natl Acad Sci USA 105: 11915-11920, 2008. 
28. Hoashi Y: Cationic Lipid. Patent WO2016021683 A1. Filed August 6, 2015; issued February 11, 2016.

29. Heyes J, Palmer L, Bremner K and MacLachlan I: Cationic lipid saturation influences intracellular delivery of encapsulated nucleic acids. J Control Release 107: 276-287, 2005.

30. Sato T, Stange DE, Ferrante M, Vries RG, Van Es JH, Van den Brink S, Van Houdt WJ, Pronk A, Van Gorp J, Siersema PD and Clevers H: Long-term expansion of epithelial organoids from human colon, adenoma, adenocarcinoma, and Barrett's epithelium. Gastroenterology 141: 1762-1772, 2011.

31. Schneeberger VE, Allaj V, Gardner EE, Poirier JT and Rudin CM: Quantitation of murine stroma and selective purification of the human tumor component of patient-derived xenografts for genomic analysis. PLoS One 11: e0160587, 2016.

32. Taromi S, Kayser G, Catusse J, von Elverfeldt D, Reichardt W, Braun F, Weber WA, Zeiser R and Burger M: CXCR4 antagonists suppress small cell lung cancer progression. Oncotarget 7: 85185-85195, 2016.

33. Wu G, Qiu XL, Zhou L, Zhu J, Chamberlin R, Lau J, Chen PL and Lee WH: Small molecule targeting the Hec1/Nek2 mitotic pathway suppresses tumor cell growth in culture and in animal. Cancer Res 68: 8393-8399, 2008.

34. Hu CM, Zhu J, Guo XE, Chen W, Qiu XL, Ngo B, Chien R, Wang YV, Tsai CY, Wu G, et al: Novel small molecules disrupting Hec1/Nek2 interaction ablate tumor progression by triggering Nek2 degradation through a death-trap mechanism. Oncogene 34: 1220-1230, 2015.

35. Pollack VA, Savage DM, Baker DA, Tsaparikos KE, Sloan DE, Moyer JD, BarbacciEG, Pustilnik LR, Smolarek TA, Davis JA, etal: Inhibition of epidermal growth factor receptor-associated tyrosine phosphorylation in human carcinomas with CP-358,774: Dynamics of receptor inhibition in situ and antitumor effects in athymic mice. J Pharmacol Exp Ther 291: 739-748, 1999.
36. Pao W, Wang TY, Riely GJ, Miller VA, Pan Q, Ladanyi M, Zakowski MF, Heelan RT, Kris MG and Varmus HE: KRAS mutations and primary resistance of lung adenocarcinomas to gefitinib or erlotinib. PLoS Med 2: e17, 2005.

37. Pao W, Miller VA, Politi KA, Riely GJ, Somwar R, Zakowski MF, Kris MG and Varmus H: Acquired resistance of lung adenocarcinomas to gefitinib or erlotinib is associated with a second mutation in the EGFR kinase domain. PLoS Med 2: e73, 2005.

38. Ekert JE, Johnson K, Strake B, Pardinas J, Jarantow S, Perkinson R and Colter DC: Three-dimensional lung tumor microenvironment modulates therapeutic compound responsiveness in vitro-implication for drug development. PLoS One 9: e92248, 2014.

39. Friedrich J, Seidel C, Ebner R and Kunz-Schughart LA: Spheroid-based drug screen: Considerations and practical approach. Nat Protoc 4: 309-324, 2009.

40. Perche F and Torchilin VP: Cancer cell spheroids as a model to evaluate chemotherapy protocols. Cancer Biol Ther 13: 1205-1213, 2012

41. Endo H, Okami J, Okuyama H, Kumagai T, Uchida J, Kondo J, Takehara T, Nishizawa Y, Imamura F, Higashiyama $M$ and Inoue M: Spheroid culture of primary lung cancer cells with neuregulin 1/HER3 pathway activation. J Thorac Oncol 8: 131-139, 2013.

42. Onion D, Argent RH, Reece-Smith AM, Craze ML, Pineda RG, Clarke PA, Ratan HL, Parsons SL, Lobo DN, Duffy JP, et al: 3-Dimensional patient-derived lung cancer assays reveal resistance to Standards-of-Care promoted by stromal cells but sensitivity to histone deacetylase inhibitors. Mol Cancer Ther 15: 753-763, 2016. 